\title{
Myriam Wattée-Delmotte, Sophiane Laghouati, Isabelle Vanquaethem, Henry Bauchau. La parole précaire
}

\section{Michele Mastroianni}

\section{(2) OpenEdition Journals}

Édition électronique

URL : https://journals.openedition.org/studifrancesi/4818

DOI : 10.4000/studifrancesi.4818

ISSN : 2421-5856

Éditeur

Rosenberg \& Sellier

\section{Édition imprimée}

Date de publication : 1 avril 2012

Pagination : 187

ISSN : 0039-2944

\section{Référence électronique}

Michele Mastroianni, « Myriam Wattée-Delmotte, Sophiane Laghouati, Isabelle Vanquaethem, Henry Bauchau. La parole précaire », Studi Francesi [En ligne], 166 (I | LVI) | 2012, mis en ligne le 30 novembre 2015, consulté le 18 novembre 2021. URL : http://journals.openedition.org/studifrancesi/4818; DOI https://doi.org/10.4000/studifrancesi.4818

Ce document a été généré automatiquement le 18 novembre 2021.

\section{cc) (†) $\odot$}

Studi Francesi è distribuita con Licenza Creative Commons Attribuzione - Non commerciale - Non opere derivate 4.0 Internazionale. 


\title{
Myriam Wattée-Delmotte, Sophiane Laghouati, Isabelle Vanquaethem, Henry Bauchau. La parole précaire
}

\author{
Michele Mastroianni
}

\section{RÉFÉRENCE}

MYRIAM WATTÉE-DELMOTTE, SOPHIANE LAGHOUATI, ISABELLE VANQUAETHEM, Henry Bauchau. La parole précaire, Bruxelles, Édition de La Maison d'à côté, 2009, pp. 160 + CD.

1 Cet ouvrage important, qui se construit sur un double axe d'intérêt et d'enquête, offre aux chercheurs un matériel original et très riche qui, entre autres, se base sur des données jusqu'à présent inédites provenant du Fonds Henry Bauchau de l'Université Catholique de Louvain. Même la perspective analytique choisie suit une nouvelle piste de recherche se focalisant, en particulier, sur la question du langage poétique et de l'élaboration bauchaliennes, par le biais aussi de témoignages de l'auteur qui se reconnaît, dans sa condition ontologique immanente, comme signe matériel de la précarité humaine et de la précarité poétique par laquelle, en écrivain, il s'exprime et se communique à son public.

2 Le livret accompagné du CD contenu dans ce coffret - un livret qui est un véritable ouvrage d'érudition, au point qu'il serait impossible ici de lui rendre justice et de le résumer en tenant compte de tous les nœuds idéologiques argumentés de manière convaincante-gravite sur un postulat fondamental de l'expérience littéraire bauchalienne, c'est-à-dire sur l'exigence nécessaire à l'auteur d'assumer, à travers la psychanalyse, son désir de s'exprimer par l'écriture, à laquelle, pourtant, il se consacra tardivement. Un postulat axé aussi sur la mise en valeur de l'inconscient, ainsi que sur le rôle qu'il jouera dans la vie tout comme dans l'élaboration poétique de l'auteur. Myriam Watthée-Delmotte, avec les co-auteurs de cet ouvrage, n'hésite pas à souligner les profondes connexions entre inconscient et psychanalyse d'une part et écriture et 
désir d'écriture de l'autre, sans pour autant négliger les rapports que ce binôme, thématique et idéologique à la fois, entrelace avec la poésie chez l'auteur. C'est en effet par la poésie que - ainsi que les éditeurs de cet ouvrage le soulignent et le rappellent à plusieurs reprises - Bauchau commence l'expérience littéraire qui lui a valu le succès de ces dernières années. Les éditeurs retracent donc, dans cette perspective de recherche, le sens de l'écriture bauchalienne en nous proposant un parcours d'investigation bâti sur de nombreuses œuvres de Bauchau. Ainsi, envisagent-elles un itinéraire analytique qui passe du Régiment Noir à $L a$ Déchirure, de l'Escalier bleu à $L a$ Sourde oreille ou le rêve de Freud, de L'Écriture à l'écoute à Pour une politique catholique etc. De ce parcours il résulte avec évidence que le sens profond de l'écriture bauchalienne est à voir et à rechercher - ainsi que l'auteur lui-même le déclare - à l'intérieur de l'enfance, dans les rapports familiers et au cœur de toute son existence. Or, si d'un côté cette étude très dense d'informations s'organise autour de certains problèmes concernant de près l'élaboration et le discours poétiques de Bauchau, de l'autre, elle ne manque pas de reconstruire les moments essentiels de la vie de l'écrivain en parallèle avec ces personnes ou ces amis, tel Raymond de Becker, le chanoine Leclercq, Jean Amrouche, Blanche Reverchon etc., dont la présence à été indiscutablement importante dans l'évolution personnelle aussi bien que dans les itinéraires spirituels ou littéraires de l'auteur. Ainsi, de la vie intime aux engagements politiques, et encore de la participation à la Guerre à la formation et à la pratique de catholique convaincu pour en arriver à la découverte de Freud et de ses écrits, l'attention des éditeurs de cet ouvrage glisse sur le poids que la Guerre et surtout les échecs de l'après-guerre, qui étaient liés aussi à l'expérience du Service des Volontaires du Travail, ont eu sur l'univers intime, spirituel et psychologique de l'auteur qui en fut profondément blessé. La première analyse avec Blanche Reverchon est emblématique de la résurgence de ces événements et du déchirement intérieur que ces circonstances douloureuses provoquèrent chez Bauchau.

3 Ce qui impressionne, en particulier, de ce travail est la rigueur analytique qui se construit lentement au fil d'un axe chronologique lié à la vie de Bauchau et qui oscille entre les années quarante et l'actualité. Les éditeurs savent fondre la première section de cet ouvrage de manière cohérente avec la deuxième. Celle-ci est représentée par un CD qui offre, à côté de l'analyse critique et thématique précédentes, un long entretien mené par Jean-Luc Outers faisant le point sur les relations et les intersections qui se créent parmi les divers genres d'écriture dans lesquels Bauchau s'essaie sans arrêt. Suivent aussi une lecture de Michael Lonsdale et de Frédéric Dussenne concernant des passages du Boulevard périphérique et une lecture d'un passage clé de L'Enfant bleu par Henry Bauchau. Ce travail hétérogène et complexe, qui se fait remarquer par sa rigueur méthodologique, est à notre avis à considérer comme un instrument fondamental pour n'importe quelle étude sur Henry Bauchau. 